\title{
Rendimento e rentabilidade das culturas da soja, milho e feijão cultivados sob condições de sequeiro
}

\author{
Profitability of soybean crop, corn and bean grown under \\ conditions of upland
}

\author{
Gisele Aparecida Vivan ${ }^{1 *}$; Adroaldo Dias Robaina ${ }^{2}$; Marcia Xavier Peiter²; \\ Ana Rita Costenaro Parizi ${ }^{3}$; Fabrício da Silva Barboza ${ }^{1}$; Fátima Cibele Soares ${ }^{4}$
}

\begin{abstract}
Resumo
O clima, em especial a disponibilidade hídrica, apresenta-se como fator limitante à obtenção de rendimentos próximos ao potencial produtivo das culturas, constituindo-se na maior causa de variabilidade interanual na produção de grãos e na renda nas diversas regiões do Brasil. Neste contexto, o presente estudo objetiva identificar e caracterizar o efeito da restrição hídrica sobre o rendimento de grãos das culturas da soja, milho e feijão e sobre os custos, a renda bruta e lucro destas, na região de Santiago, RS. Para tanto, foi utilizado o sistema DSSat calibrado e validado para as condições e culturas em estudo, sendo utilizado o período histórico 1961-2010 para geração dos dados de produção referentes a cada safra. Os dados obtidos foram adimensionalizados tomando como base a produção potencial de cada cultura, sendo elaborado histograma de frequência para avaliação do risco de quebra de produção referente a cada safra. Posteriormente foram utilizadas séries de dados históricos de custos e preços de venda das culturas em estudo do mesmo período para realização de análise econômica simplificada. Em termos de produção, o feijão, o milho e a soja em $65 \%, 50 \%$ e $41 \%$ dos anos, respectivamente, obtiveram produções abaixo de $50 \%$ do potencial destas culturas. Em termos econômicos, o maior custo; renda bruta e lucro médio estão associado a cultura do milho, seguidos pela cultura do feijão e da soja, respectivamente. As três culturas, soja, milho, feijão, apresentaram significativas reduções de produção e consequentemente de lucro em função da restrição hídrica.
\end{abstract}

Palavras-chave: Modelagem computacional, disponibilidade hídrica, Glycine max L., Zea mays L., Phaseolus vulgaris $L$.

\begin{abstract}
The climate, particularly water availability, presents itself as a limiting factor to obtain yields close to the productive potential of crops, being the major cause of interannual variability in grain production and income in different regions of Brazil. In this context, this study aims to identify and characterize the effect of water stress on the yield of soybean crops, maize and beans and on the costs, gross income and profit from these in the region of Santiago, RS. Therefore, we used the calibrated DSSAT system and validated for the conditions and cultures being studied, and used the historical period 1961-2010 to generate production data for each crop. Data were adimensionalizados building on the potential production of each culture, establishing frequency histogram for assessing the risk of production loss in respect of each crop. Later they used historical data series costs and selling prices of crops in the
\end{abstract}

\footnotetext{
${ }^{1}$ Profs. Mestres, Instituto Federal Sul-Riograndense, IFSul, Bagé, RS. E-mail: giselevivan@gmail.com.br; f.barboza@yahoo.com

2 Profs. Drs., Programa de Pós-Graduação Engenharia Agrícola, Universidade Federal de Santa Maria, UFSM, CCR, Santa Maria, RS. E-mail: diasrobaina@gmail.com; mpeiter@gmail.com

3 Prof ${ }^{\mathrm{Dr}} \mathrm{r}^{\mathrm{a}}$, Instituto Federal Farroupilha, IFF, Alegrete, RS. E-mail: anaparizi@gmail.com

${ }^{4} \mathrm{Prof}^{\mathrm{a}} \mathrm{Dr}^{\mathrm{a}}$, Universidade Federal do Pampa, UNIPAMPA, Alegrete, RS. E-mail: fatimacibele1@gmail.com

* Autor para correspondência
} 
same study period for performing simplified economic analysis. In terms of production, bean, corn and soybeans in $65 \%, 50 \%$ and $41 \%$ of the years, respectively, achieved yields below $50 \%$ of the potential of these crops. In economic terms, the biggest cost; gross income and average income are associated with corn, followed by the bean crop and soybean, respectively. The three crops, soybean, corn, beans, showed significant reductions in production and consequently profit depending on water restriction.

Key words: Computational modeling, water availability, Glycine max L., Zea mays L., Phaseolus vulgaris $L$.

\section{Introdução}

Oagronegócio, considerado como todo o conjunto de negócios que se relacionam com a agricultura, dentro de uma visão econômica, é o responsável, segundo o Ministério do Desenvolvimento, Indústria e Comércio Exterior (MDIC, 2008), por cerca de $1 / 3$ do PIB do Brasil, alocando aproximadamente $38 \%$ da mão-de-obra do país e responsabilizando-se por $42 \%$ das nossas exportações.

Segundo Ruas et al. (2008) é clara a vocação e o potencial atual e futuro do Brasil e do Rio Grande do Sul para o agronegócio, salientando-se a crescente demanda de alimentos a nível mundial, a utilização de novas tecnologias, os investimentos em produção, em pesquisa e desenvolvimento e a possibilidade de utilização de áreas agricultáveis inexploradas.

No entanto, o setor do agronegócio apresenta diversos fatores que o tornam uma atividade de alto risco, sendo a condição climática um dos principais. Diversos autores citam que as variáveis climáticas podem influenciar fortemente o resultado final de uma safra, pois a produção é dependente desta. Ozaki (2007) afirma que dentre estas variáveis, salienta-se a disponibilidade hídrica, onde sua restrição pode afetar significativamente o resultado potencial da cultura, em especial quando ocorrer durante determinadas fases do ciclo de desenvolvimento.

Trabalhos como os de Mota et al. (1996), Cunha et al. (1998) e Matzenauer et al. (1998) relatam que a baixa disponibilidade hídrica apresenta-se como fator limitante ao elevado rendimento de grãos de soja e de milho no Rio Grande do Sul, fato esse que, por analogia e similaridade nas estações de crescimento, pode ser estendido à cultura de feijão (MALUF et al., 2001).
Deste modo, a avaliação do efeito de variações climatológicas sobre a produção das culturas é fator fundamental para a previsão das safras agrícolas. Sendo os modelos agrometeorológicos ferramentas úteis para a interpretação dessa variabilidade climática na produção vegetal (MORAES et al., 1998).

Elevado percentual dos trabalhos disponíveis na literatura utilizando modelos agrometereologicos faz uso de algum fator ligado à disponibilidade hídrica como variável independente para análise, como a precipitação pluvial, evapotranspiração potencial e real e a deficiência hídrica (CALVE, 2011).

A escassez hídrica impõe estresses abióticos, que são os fatores mais importantes na limitação da capacidade produtividade da planta, sendo o suprimento artificial de água, via irrigação, importante instrumento para amenizar os impactos das oscilações climáticas sobre a produção agrícola (AMUDHA; BALASUBRAMANI, 2011).

Segundo Fernandes (2012), na região noroeste de Minas Gerais, um aumento na produtividade pode não refletir em um aumento na lucratividade do produtor rural, tendo em vista que, muitas vezes, pode não haver um retorno financeiro satisfatório ao investimento executado. Neste contexto, é importante a elaboração de estudos de viabilidade que disponibilizem informações relevantes para a correta tomada de decisão dos produtores, diminuindo as condições de incertezas em relação ao retorno esperado de seu investimento.

Desse modo, o presente estudo objetiva identificar e caracterizar o efeito da restrição hídrica sobre o rendimento de grãos das culturas da soja, milho e feijão e sobre os custos, a renda bruta e lucro destas, na região de Santiago, RS. 


\section{Material e Métodos}

O estudo foi desenvolvido para a região de Santiago, RS, sendo que as etapas de experimentações a campo para calibração do modelo para as culturas da soja, milho e feijão, foram realizadas na Fazenda Liberdade, $4^{\circ}$ Distrito Tupantuba, estrada Chica Correia e encontra-se descrita em detalhes em Parizi (2010) e Gomes (2011).

Foram utilizadas as culturas da soja, cultivar Coodetec 219 (CD 219), do milho, cultivar Pioneer 32R22 e, do feijão, cultivar Uirapuru (IPR 88), sendo inseridos os coeficientes genéticos a ser utilizados no sistema DSSat (Decision support system for agrotechnology transfer), em seus módulos soja, milho e feijão (VIVAN, 2014).

Para as simulações foram utilizados dados climáticos do período histórico 1961-2010 obtidos em estação automática oficial do INMet de São Luis Gonzaga, sendo estes: precipitação (mm.dia $\left.{ }^{-1}\right)$; temperatura máxima e mínima $\left({ }^{\circ} \mathrm{C}\right)$; radiação solar $\left(\mathrm{MJ} \cdot \mathrm{m}^{-2} \cdot \mathrm{dia}^{-1}\right.$ ) e brilho solar (horas).

Para as simulações optou-se pela utilização do sistema DSSat nos seus módulos para a cultura da soja, Cropgro-Soybean, do milho, Ceres Maize e, do feijão, Cropgro-Drybean. Foram realizadas as simulações e determinados os valores referentes a resposta produtiva: produção de grãos $(\mathrm{PG})$, para as culturas, nas safras do período histórico em estudo. Cita-se que na modelagem desconsiderouse o período 1978 à 1991 e 2000 à 2001, haja visto as séries de dados de clima apresentarem-se incompletas.

Os valores referentes a produção de grãos (PG) para as três culturas foram adimensionalizados tomando como base a produção potencial da cultura determinada experimentalmente por Parizi (2010) e Gomes (2011), sendo estas para a cultura da soja, milho e feijão, de 3.428; 15.550 e 4098 kg.ha-1, respectivamente. Sendo construídos histogramas de frequência a partir destes dados a fim de avaliar o risco de quebra de produção referente a cada safra.
Posteriormente foram utilizadas séries de dados históricos de custos e preços de venda das culturas da soja, milho e feijão para realização da análise econômica do período histórico em estudo. Para isto foram obtidos os valores referentes aos custos de produção destas culturas junto ao relatório: Tendências dos mercados para 2012/2013 no Brasil e no Mundo (COGO, 2012), sendo utilizado o valor médio de custo no presente ano.

Os preços de venda foram obtidos junto ao relatório da CONAB (2013), sendo realizada a média dos valores de referência para o Rio Grande do Sul, dos meses de janeiro e fevereiro de 2013, para as culturas em estudo. A determinação do lucro foi obtida pela diferença entre a renda obtida e os custos de produção, conforme apresentado na Equação 1.

$$
\begin{gathered}
\text { Lucro }\left(R \$ . h a^{-1}\right)= \\
\text { Renda Bruta }\left(R \$ . h a^{-1}\right)-\text { Custos Totais }\left(R \$ . h a^{-1}\right)
\end{gathered}
$$

\section{Resultados e Discussão}

São apresentados na Figura 1 os histogramas de frequência adimensionalizados para a produção de grãos no período entre safras 1961-2010 para as culturas da soja (a), milho (b) e feijão (c) na Região de Santiago-RS.

Observando os valores referentes a frequência relativa, nota-se que para a cultura da soja, a maior parte dos dados $(20,59 \%)$ enquadram-se na classe 2 , isto é, a produção estimada para o período entre safras está entre 70 à $79 \%$ da produção potencial da cultura em aproximadamente 7 safras, visto terem sido analisadas 34 safras. No geral, em 70\% dos anos, a produção prevista via modelagem esteve superior a $40 \%$ da produção potencial da cultura. Estas reduções de produção advindas da variabilidade climática também são citadas por Berlato e Fontana (2003) que estimam que 93\% das perdas nas safras de soja sejam em razão do déficit hídrico. 
Figura 1. Histogramas da produção relativa (relação entre produção potencial e produção obtida), no período entre safras 1961-2010 para as culturas da soja (a), milho (b) e feijão (c), na Região de Santiago, RS.
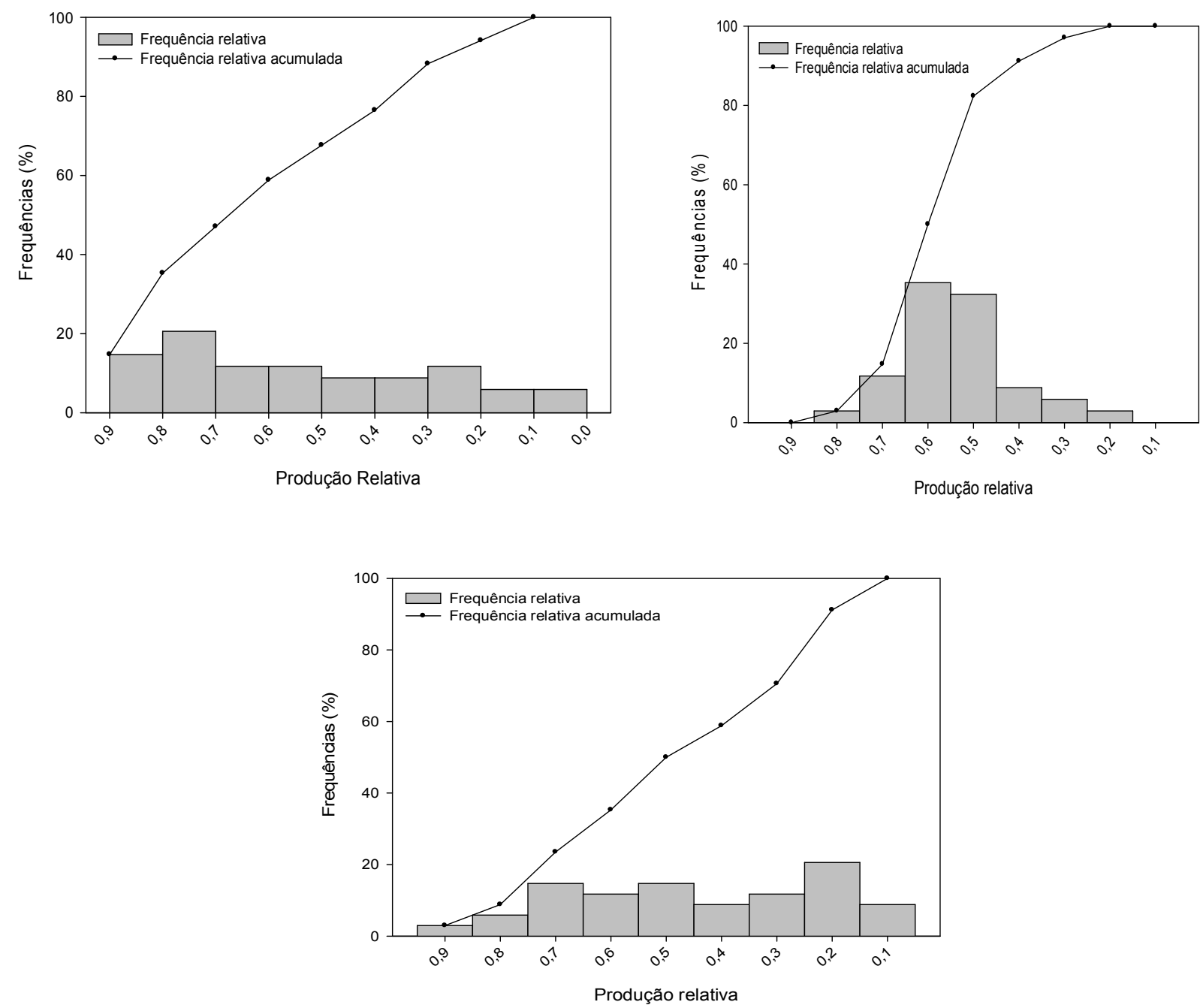

Fonte: Elaboração dos autores.

Cita-se ainda que os 76\% dos valores de produção prevista obtidas via simulação para a cultura da soja encontram-se entre os valores de produção observados pelo Instituto Brasileiro de Geografia e Estatística (IBGE, 2010), que, entre 1990 a 2008, variaram de 666 a $2.400 \mathrm{~kg} \cdot \mathrm{ha}^{-1}$ para o Estado do Rio Grande do Sul.

Para a cultura do milho nota-se que, em $67,64 \%$ dos anos estudados, a produção prevista esteve entre 40 e $60 \%$ da produção potencial da cultura. Resultados semelhantes foram encontrados por Bergamaschi et al. (2006), que constataram alta sensibilidade ao déficit hídrico, dos hídricos Pioneer
3230, 3063 e 32R22, e observaram ainda redução de produtividade na ordem de 44, 29 e 25\%, respectivamente, quando comparado a ausência de deficiência hídrica, para estudos realizados com estas cultivares, em Eldorado do Sul, no período de 1994/1995 a 2002/2003.

Bergamaschi et al. (2004) citam ainda que pode ocorrer redução de rendimento mesmo em anos climaticamente favoráveis, se o deficit hídrico ocorrer no período crítico de desenvolvimento da cultura do milho, ou seja, da pré-floração ao início de enchimento de grãos. 
Para a cultura do feijão, na maior parte dos anos (20,59\%), a produção prevista esteve entre 10 e $19 \%$ da produção potencial da cultura, existindo elevada variabilidade em termos de níveis produtivos desta ao longo dos anos. As elevadas reduções de rendimento ocorridas no presente trabalho, também foram observadas por Aguiar et al. (2008) que trabalhando com avaliação de linhagens de feijoeiro classificadas como moderadamente tolerante ao déficit hídrico, encontraram redução de rendimento de 70,5\%, para as plantas do grupo preto (IPR Uirapuru), em Londrina-PR, na safra agrícola 2002/2003.

Assim, dentre as culturas utilizadas no presente trabalho, a mais atingida pela variabilidade climática foi a do feijão, onde em aproximadamente $65 \%$ dos anos a produção obtida esteve abaixo de $50 \%$ da produção potencial; seguida pela cultura do milho onde em $50 \%$ dos anos a cultura obteve produção abaixo de $50 \%$ do potencial da cultura e da soja onde, em aproximadamente $41 \%$ dos anos, ocorreu mesmo fato.

Na Figura 2 é apresentada a evolução dos valores de custos de produção, preços e margens de lucro obtidos com as culturas da soja (a), milho (b) e feijão (c), no período em estudos (1961-2010), na Região de Santiago-RS.

Para a cultura da soja, os custos variaram entre $\mathrm{R} \$ 78,00 . \mathrm{ha}^{-1}$ e $\mathrm{R} \$ 1.642,00$. ha- $\mathrm{h}^{-1}$, com rendas brutas entre $\mathrm{R} \$ 138,00$. ha- ${ }^{-1}$ e $\mathrm{R} \$ 2.878,00$. ha $\mathrm{h}^{-1}$ e lucros entre $\mathrm{R} \$ 59,00$. ha ${ }^{-1}$ e $\mathrm{R} \$ 1.236,00$. ha-1. De modo geral, o custo, renda e lucro, foram de: $\mathrm{R} \$ 979,00$; $\mathrm{R} \$ 1.716,00$ e $\mathrm{R} \$ 737,00$; respectivamente. Os valores médios referentes a custo e lucro para o período estudado (1961-2010) estão próximos aos valores encontrados por Hirakuri (2011) que, considerando uma cotação de $\mathrm{R} \$ 45,00$ para a saca de $60 \mathrm{~kg}$, obteve receitas de vendas variando de
$\mathrm{R} \$ 2.070,00$. ha ${ }^{-1}$ a $\mathrm{R} \$ 2.340,00 \cdot \mathrm{ha}^{-1}$, custos totais entre R\$1.299,28. ha-1 e R\$ 1.366,71. ha-1, e lucros líquidos entre $\mathrm{R} \$ 770,72 \cdot \mathrm{ha}^{-1}$ e $\mathrm{R} \$ 987,40 \cdot \mathrm{ha}^{-1}$.

Para a cultura do milho, os custos variaram entre $\mathrm{R} \$$ 956,00. ha ${ }^{-1}$ e R $\$ 4.030,00$. ha $^{-1}$, com rendas brutas entre $\mathrm{R} \$ 1.273,00$. ha-1 e $\mathrm{R} \$ 5.363,00$. ha $\mathrm{ha}^{-1}$ e lucros de $\mathrm{R} \$ 316,00$. ha ${ }^{-1}$ e $\mathrm{R} \$ 1.333,00$. ha ${ }^{-1}$. De modo geral, o custo, renda e lucro, são de: R\$ 2.704,00. ha-1; R\$ 3.599,00. ha ${ }^{-1}$ e R\$ 895,00. ha-1; respectivamente. Já na cultura do feijão, os custos variaram entre $\mathrm{R} \$ 160,00 . \mathrm{ha}^{-1}$ e $\mathrm{R} \$ 4.918,00$. $\mathrm{ha}^{-1}$, com rendas brutas entre $\mathrm{R} \$ 211,00$. ha $\mathrm{h}^{-1} \mathrm{e}$ R\$ 6.485,00. ha-1 e lucros de R\$ 51,00. ha-1 e R\$ $1.567,00 \mathrm{ha}^{-1}$. De modo geral, o custo, renda e lucro, são de: R\$ 2.332,00. ha-1; R\$ 3.076,00. ha-1 e R\$ 743,00 . ha ${ }^{-1}$; respectivamente.

Assim, dentre as culturas e para o período em estudo, a cultura da soja foi a que apresentou os menores custos de produção, enquanto a cultura do milho apresentou custo mínimo significativamente elevado, e a do feijão apresentou maior variação entre custos mínimos e máximos. Quanto a renda bruta e lucro a situação é semelhante, cita-se ainda que para o período histórico em estudo apresenta-se com menor variação nos lucros a cultura do milho; o que apresenta-se interessante do ponto de vista de segurança para o agricultor.

Assim, se considerada a definição de pequeno agricultor fornecida pelo MDA para concessões do Pronaf, que diz que o pequeno agricultor é aquele que possui até 4 módulos fiscais (MDA, 2013), para a região de Santiago, este são os que possuem até 140 hectares. Com isto, o lucro médio advindo na produção de soja, milho e feijão, considerando a máxima área para um produtor ser considerado pequeno é de $\mathrm{R} \$ 103.180,00 ; \mathrm{R} \$ 125.300,00$; $\mathrm{R} \$ 104.020,00$ anuais, respectivamente. 
Figura 2. Evolução dos valores de custos de produção, preços e margens de lucro obtidos com as culturas da soja (a), milho (b) e feijão (c), no período em estudos (1961-2010), na Região de Santiago, RS
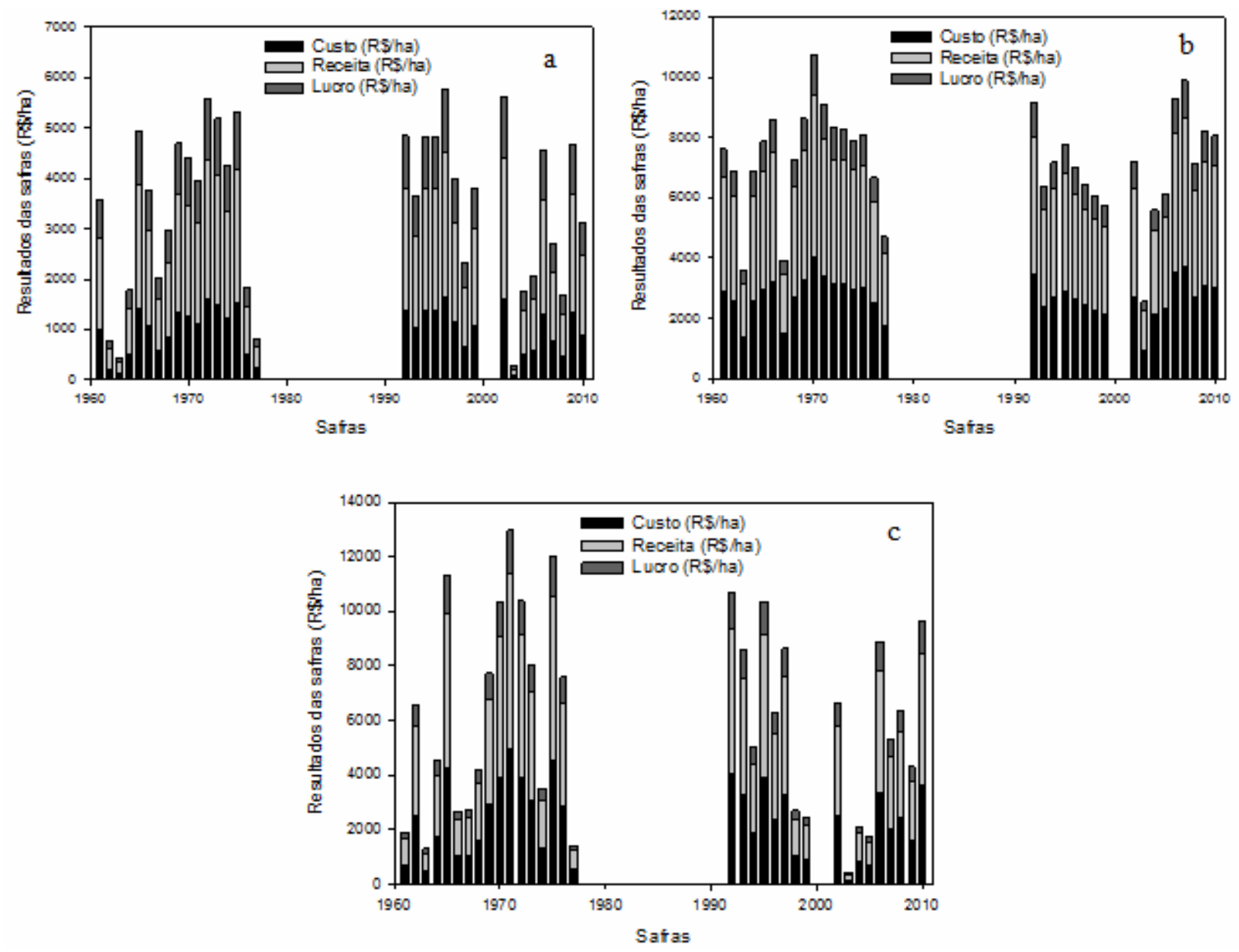

Fonte: Elaboração dos autores.

Acultura que apresentou o maior lucro por hectare foi a do milho, que considerando os 12 meses do ano, apresenta uma renda mensal por propriedade de $\mathrm{R} \$ 10.441,66$, assim para uma família com 4 pessoas, a renda per capita mensal gerada foi de $\mathrm{R} \$ 2.610,41$, admitindo a renda per capita média do município de $\mathrm{R} \$ 777,06$, esta a renda gerada com o cultivo é mais de 3 vezes superior a renda per capita do município.

Cita-se ainda, que, para a cultura da soja, em $29 \%$ dos anos em estudo o lucro por hectare foi inferior à R $\$ 451,00$; em 24\% dos anos esteve entre $\mathrm{R} \$ 451,00$ e R\$844,00 e em 47\% dos anos foi acima de $\mathrm{R} \$ 844,00$. Para a cultura do milho em $12 \%$ dos anos o lucro por hectare foi inferior à $\mathrm{R} \$ 655,00$; em $53 \%$ dos anos esteve entre $\mathrm{R} \$ 655,00$ e $\mathrm{R} \$ 995,00$ e em $35 \%$ dos anos foi acima de $\mathrm{R} \$ 995,00$. Na cultura do feijão, em $41 \%$ dos anos o lucro por hectare foi inferior à R \$ 557,00; em 32\% dos anos esteve entre $\mathrm{R} \$ 557,00$ e $\mathrm{R} \$ 1.062,00$ e em $27 \%$ dos anos foi acima de $\mathrm{R} \$ 1.062,00$.

\section{Conclusões}

Reduções superiores a $50 \%$ da produção potencial de grãos das culturas de feijão, milho e soja em são constatadas em mais de $40 \%$ dos anos em estudo. 
Os maiores custos totais; renda bruta e lucro médio estão associados a cultura do milho, seguidos pela cultura do feijão e da soja. O lucro final não acompanha mesma tendência, indicando maiores riscos de descapitalização do milho e do feijão em caso de reduções de produtividade.

Para as condições de estudo, as três culturas estudadas, soja, milho, feijão, apresentaram significativas reduções de produção e consequentemente lucro em função da variabilidade climática.

\section{Agradecimentos}

Ao Programa de Pós-graduação em Engenharia Agrícola pelo apoio técnico e financeiro. E ao INMET pela cedência dos dados climáticos.

\section{Referências}

AGUIAR, R. S.; MODA-CIRINO, V.; FARIA, R. T.; VIDAL, L. H. I. Avaliação de linhagens promissoras de feijoeiro (Phaseolus vulgaris L.) tolerantes ao déficit hídrico. Semina: Ciências Agrárias, Londrina, v. 29, n. 1, p. 1-14, 2008.

AMUDHA, J.; BALASUBRAMANI, G. Recent molecular advances to combat abiotic stress tolerance in crop plants. Biotechnology and Molecular Biology Reviews, Washington, v. 6, n. 2, p. 31-58, 2011.

BERGAMASCHI, H.; DALMAGO, G. A.; BERGONCI, J. I.; BIANCHI, C. A. M.; MÜLLER, A. G.; COMIRAN, F.; HECKLER, B. M. M. Distribuição hídrica no período crítico do milho e produção de grãos. Pesquisa Agropecuária Brasileira, Brasília, v. 39, n. 9, p. 831-839, 2004.

BERGAMASCHI, H.; DALMAGO, G. A.; COMIRAN, F.; BERGONCI, J. I.; MÜLLER, A. G.; FRANÇA, S.; SANTOS, A. O.; RADIN, B.; BIANCHI, C. A. M.; PEREIRA, P. G. Déficit hídrico e produtividade na cultura do milho. Pesquisa Agropecuária Brasileira, Brasília, v. 41, n. 2, p. 243-249, 2006.

BERLATO, M. A.; FONTANA, D. C. El Niño e La Niña: impactos no clima, na vegetação e na agricultura do Rio Grande do Sul; aplicações de previsões climáticas na agricultura. Porto Alegre: UFRGS, 2003. 110 p.
CALVE, L. Estimativa de perda potencial de soja no Paraná através de métodos agrometeorológicos para fins de seguro agrícola. 2011. Dissertação (Mestrado em Engenharia Agrícola) - Universidade Estadual de Campinas, Campinas.

COGO, C. Grãos: soja, milho, trigo e arroz. Tendências dos mercados para 2012/2013 no Brasil e no mundo. Porto Alegre: Notícias Agrícolas, 2012. Disponível em: $<$ http://www.noticiasagricolas.com.br/dbarquivos /grosrelatrio-tendncias-mercados-2012-2013.pdf $>$. Acesso em: 20 set. 2009.

COMPANHIA NACIONAL DE ABASTECIMENTO CONAB. Acompanhamento de safra brasileira: grãos, intenção de plantio, segundo levantamento de novembro 2013. Companhia Nacional de Abastecimento. Brasília: Conab, 2013.

CUNHA, G. R. da; HAAS, J. C.; DALMAGO, G. A.; PASINATO, A. Perda de rendimento potencial em soja no Rio Grande do Sul por deficiência hídrica. Revista Brasileira de Agrometeorologia, Santa Maria, v. 6, n. 1, p. 111-119, 1998.

FERNANDES, L. M. Retorno financeiro e risco de preço da cultura do feijão irrigado via pivô central na região noroeste de minas gerais. Informações Econômicas, São Paulo, v. 42, n. 1, p. 41-53, 2012.

GOMES, A. C. S. Estudo experimental e simulado da cultura da soja em função de diferentes níveis de irrigação. 2011. Tese (Doutorado em Engenharia Agrícola) - Universidade Federal de Santa Maria, Santa Maria.

HIRAKURI, M. H. Avaliação do desempenho econômico-financeiro da produção de soja nos estados do Rio Grande do Sul e de Santa Catarina, para a safra 2011/12. Londrina: Embrapa Soja, 2011. 10 p.

INSTITUTO BRASILEIRO DE GEOGRAFIA E ESTATÍSTICA - IBGE. Produção agrícola municipal. Rio de Janeiro: IBGE, 2010. Disponível em: <http:// www.ibge.gov.br>. Acesso em: 12 mar. 2013.

MALUF, J. R. T.; CUNHA, G. R.; MATZENAUER, R.; PASINATO, A.; PIMENTEL, M. B.; CAIOFFO, M. R. Zoneamento de riscos climáticos para a cultura de feijão no Rio Grande do Sul. Revista Brasileira de Agrometeorologia, Passo Fundo, v. 9, n. 3, p. 468-476, 2001. Número Especial.

MATZENAUER, R.; BERGAMASCHI, H.; BERLATO, M. A.; MALUF, J. R. T. Evapotranspiração da cultura do milho. I - Efeito de épocas de semeadura. Revista Brasileira de Agrometeorologia, Santa Maria, v. 6, n. 1, p. 9-14, 1998. 
MINISTÉRIO DO DESENVOLVIMENTO AGRÁRIO - MDA. Cartilha terra legal: áreas rurais. Brasília: [s.n.], 2013. Disponível em: <http://www.agricultura.gov.br/ portal>. Acesso em: 14 jan. 2013.

MINISTÉRIO DO DESENVOLVIMENTO, INDÚSTRIA E COMÉRCIO EXTERIOR - MDIC. Intercâmbio comercial brasileiro, por países: 1953 a 1976. Brasília: [s.n.], 2008. Disponível em: <http://www.mdic. gov.br/sitio/interna/interna.php?area $=5 \&$ menu $=1955>$. Acesso em: 10 fev. 2013.

MORAES, A. V. C.; CAMARGO, M. B. P.; MASCARENHAS, H. A. A.; MIRANDA, M. A. C.; PEREIRA, J. C. V. N. A. Teste e análise de modelos agrometeorológicos de estimativa de produtividade para a cultura da soja na região de Ribeirão Preto. Bragantia, Campinas, v. 57, n. 2, p. 393-406, 1998.

MOTA, F. S. da; AGENDES, M. O. de O.; ALVES, E. G. P.; SIGNORINI, E. Análise agroclimatológica da necessidade de irrigação da soja no Rio Grande do Sul. Revista Brasileira de Agrometeorologia, Santa Maria, v. 4, n. 1, p. 133-138, 1996.
OZAKI, V. A. O papel do seguro na gestão do risco agrícola e os empecilhos para o seu desenvolvimento. Revista Brasileira de Risco e Seguro, Rio de Janeiro, v. 2, n. 4, p. 75-92, 2007.

PARIZI, A. R. C. Funções de produção das culturas de milho e feijão através de estudo experimental e simulado. 2010. Tese (Doutorado em Engenharia Agrícola) Universidade Federal de Santa Maria, Santa Maria.

RUAS, D. T.; ANTUNES, A.; MORO, M.; BRAUN, L. C.; PALMEIRA, E. M. A economia e o agronegócio no Brasil e Sul do Brasil. Revista Acadêmica de Economia, Observatorio de la Economía Latinoamericana, Málaga, v. 15, n. 105, 2008.

VIVAN, G. A. Simulação dinâmica da soja, milho e feijão, cultivados sob diferentes regimes hídricos. 2014. Tese (Doutorado em Engenharia Agrícola) - Universidade Federal de Santa Maria, Santa Maria. 